\title{
Evaluation of chronic head and neck myofascial pain control with Yamamoto New Scalp Acupuncture in eight weeks follow-up period*
}

\author{
Avaliação do controle da dor miofascial crônica em cabeça e pescoço utilizando a técnica \\ Nova Crânio Acupuntura de Yamamoto em acompanhamento durante 8 semanas
}

Luci Mara França Correia' ${ }^{1}$, Daisy Alberti ${ }^{1}$, Sandra Silvério Lopes ${ }^{1}$

${ }^{*}$ Received from Brazilian Institute of Therapies and Teaching, School of Technology and Research, Curitiba, PR, Brazil.

DOI 10.5935/1806-0013.20150016

\section{ABSTRACT}

BACKGROUND AND OBJECTIVES: Chronic pain is a common complaint in health assistance settings, so this study aimed at evaluating the analgesic efficacy of an acupuncture technique to relieve pain in patients with chronic head and neck myofascial pain.

METHODS: Participated in the study 20 volunteers (aged between 23 and 46 years) with head and neck pain for more than 3 months who presented tense myofascial bands diagnosed by the evaluator. Pain intensity at the beginning of the study was recorded by the verbal numeric scale, as well as mean pain during each week among 8 applications. Acupuncture needle $0.25 \times 30$ $\mathrm{mm}$ was used on cranial points to the right or left side of the face, determined by Yamamoto's ScalpAcupuncture technique and was maintained for 20 minutes.

RESULTS: Mean pain at beginning of treatment was 7.9 and after 8 weeks it had decreased to 0.8 , which is a significant result with $\mathrm{p}<0.05$. Pain improvement evaluation at consultation moment was also relevant because $100 \%$ of participants have reported pain improvement immediately after needle application. CONCLUSION: Our results show the effectiveness of one of different possibilities provided by acupuncture for pain relief, especially when the aim is immediate pain decrease. Although promising, results of Yamamoto New Scalp Acupuncture still need further studies to evaluate this acupuncture modality to expand its application and reliability of the technique.

Keywords:Acupuncture, Chronic pain, Headache, Myofascial pain syndromes, Neck pain.

1. School of Technology and Research, Brazilian Institute of Therapies and Teaching, Curitiba, PR, Brazil.

Submitted in July 16, 2014.

Accepted for publication in April 15, 2015.

Conflict of interests: none - Sponsoring sources: none.

Correspondence to:

Luci Mara França Correia

Rua Voluntários da Pátria, 215 - Centro

80020-000 Curitiba, PR, Brasil.

E-mail: draluci.odonto@gmail.com

(C) Sociedade Brasileira para o Estudo da Dor

\section{RESUMO}

JUSTIFICATIVA E OBJETIVOS: A dor crônica tem sido queixa constante nos atendimentos clínicos na área da saúde, dessa forma este estudo teve como objetivo avaliar a eficácia analgésica de uma técnica de acupuntura no alivio de sintomas dolorosos de pacientes com dor crônica miofascial em cabeça e pescoço.

MÉTODOS: Participaram do estudo 20 voluntários (idade entre 23 e 46 anos) com queixa de dor em cabeça e pescoço há mais de 3 meses que apresentavam bandas tensas miofasciais diagnosticadas pelo avaliador. A intensidade de dor no início da pesquisa foi registrada pela escala numérica verbal, bem como a média de dor durante cada semana entre as 8 consultas de aplicação. Foi utilizada agulha de acupuntura $0,25 \times 30 \mathrm{~mm}$ nos pontos cranianos do lado direito ou esquerdo da face, determinados pela técnica de cranioacupuntura de Yamamoto New ScalpAcupuncturemantida por 20 minutos.

RESULTADOS: A média atribuída à dor no inicio do tratamento foi 7,9 e após 8 semanas reduziu-se para 0,8 , resultado significativo sendo $\mathrm{p}<0,05$. A avaliação de diminuição da dor no momento da consulta também foi relevante, pois $100 \%$ dos participantes relataram melhora da dor após a aplicação imediata da agulha.

CONCLUSÁO:Os resultados deste estudo apontam para a eficácia de uma das diversas possibilidades que a acupuntura apresenta para o alívio de sintomas álgicos principalmente quando se busca diminuição imediata da dor. Embora os resultados com a técnicaYamamoto New ScalpAcupuncturesejam promissores, estudos ainda são necessários para avaliar essa modalidade de acupuntura para ampliar sua aplicação e confiança na técnica.

Descritores: Acupuntura, Cefaleia, Cervicalgia, Dor crônica, Síndromes da dor miofascial.

\section{INTRODUCTION}

Pain is a major biological phenomenon for body defense, however chronic pain (CP) is a disease which should be diagnosed and controlled. Currently there is increasing search for the management of CP persisting for more than three or six months, affecting 7 to $15 \%$ of adult population and bringing severe physical limitations, distress and economic losses ${ }^{1}$. Orofacial pain (OFP) is also characterized as chronic pain and 
it is estimated that 4 to $8 \%$ of Brazilian population suffer of this disorder, with symptoms related to head, face, neck and oral cavity structures, including headaches, temporomandibular joint (TMJ) and masticatory muscles pain, toothache, skull base and neck muscles pain ${ }^{2}$.

Myofascial painful syndrome (MPS) is orofacial pain responsible for the hypersensitivity of palpable strained bands of muscle fibers due to the presence of painful points called trigger-points (TP $)^{3}$ located in the muscle, muscle fascia and/or tendons. It is related to muscle activity overload or repetitive traumas causing abnormal stress in specific muscle groups, leading to decreased movement amplitude, muscle stiffness, weakness and autonomic phenomena ${ }^{3,4}$.

Chronic OFP treatment should be multidisciplinary, including a combination of patients' education, physiotherapy and drugs. Non-pharmacological treatments may be part of this action such as: manual therapy, thermal therapy, acupuncture, trigger-point dry needling, local steroid injection or surgical procedures for more advanced cases 5 .

Acupuncture is one of the oldest treatment modalities and has been successfully practiced in China for 4000 years, being traditionally used to treat different mental and physical disorders. Classic acupuncture is based on the vital energy theory (QI), which circulates in the body through meridians. There are specific points along these meridians (acupuncture points or acupoints) where Qi may be accessed. By inserting needles on these points, one is able to harmonize the system, rebalancing Qi, thus decreasing painful symptoms ${ }^{6}$.

In Western medical model, acupuncture relieves pain through the gate control theory mechanism or by neurotransmitters release ${ }^{7}$. Pomeranz \& Berman ${ }^{8}$ have described possible neural mechanisms of analgesia by acupuncture: small diameter afferent muscles are stimulated, sending impulses to the spinal cord, which then activates three centers (spinal cord, midbrain and pituitary gland) to release neurotransmitters (endorphins and monoamines) which block pain messages.

In addition to traditional acupuncture using points following their meridians, there are other acupuncture techniques which use micro systems, that is, human body regions with energetic representation in micropoints and microchannels portraying the topology of the whole body ${ }^{7}$. Among these regions, there are: ear, back of the hand, foot, abdomen and skull. The body is anatomically and functionally represented in these micro systems and when such points are punctured they stimulate distant body areas?

Skull acupuncture with Yamamoto's New Scalp Acupuncture (YNSA), which has been published for the first time in 1973, is performed in skull points bilaterally located which reflect the whole human body on a small area being the frontal region Yin and the occipital region Yang ${ }^{6}$. One indication of this technique is chronic locomotor system pain $^{10-15}$.

This study aimed at evaluating the micro system skull acupuncture technique YNSA to control myofascial pain, measuring possible pain frequency and intensity decrease on patients with head and neck CP. This is a low cost technique and a minimally invasive procedure ${ }^{5}$ which is still not widely used in Brazil and which deserves further investigation about its actions.

\section{METHODS}

This was a longitudinal, interventionist study carried out from July to October 2013 and from July to October 2014. People with painful symptoms on face, head and neck for more than six months were invited to participate in the study. E-mail and charts in the School of Technology and Research (IBRATE) were used as means of communication. Fifty-four individuals presented to participate in the study with pain on masseter, temporal, sternocleidomastoid, trapezius and suboccipital muscles. Volunteers were evaluated by a OFP specialist having as tool muscle palpation to evaluate the presence of strained band and myofascial TP with referred pain, that is, pain at palpation with irradiation to a site different from the stimulated one.

Thirty-four volunteers have met inclusion criteria which were: head and neck myofascial pain for more than six months, bilateral, with the presence of strained band at clinical evaluation in at least three areas of described muscles and pain frequency above three times a week.

Exclusion criteria were individuals undergoing some type of pain treatment during the research period, people with altered blood pressure or with circulatory problems, due to incompatibility of such alterations with the technique to be used.

Some simultaneous treatments were not allowed during the two weeks preceding the study, such as use of opioids, invasive therapy methods, non-steroid drugs, anti-inflammatory drugs, topic steroids, neuromuscular blockers, analgesics, heat, massage and cold therapy.

All patients have signed the Free and Informed consent Term (FICT) before the study.

Volunteers were oriented about the need to attend the institution's ambulatory once a week for assistance. During the following week they should fill a pain diary with pain site, frequency and intensity. The verbal numerical scale (VNS) was used to measure pain, that is, participants would score their pain from zero to 10 , where "zero" meant no pain and " 10 " the worst imaginable pain.

In the same diary, they were asked to record worsening factors such as diet or menstrual period. In case of a major pain intensity variation, volunteer was asked to check and report in the diary whether there had been any emotional involvement during the period.

At every visit, the diary was evaluated and mean pain intensity in that week was recorded, as well as pain intensity at consultation and symptoms relief or not after the application of the technique, also using VNS.

Eight sessions were performed following the sequence: point IG4 (Hegu) evaluation on right and left hands; most painful side of the hand would determine the side of the face to receive the $0.25 \times 30 \mathrm{~mm}$ needle which was inserted oblique to the skull in the specific region of the technique (points A, B or both) with patient in the sitting position. Insertion depth was 5 to $15 \mathrm{~mm}$ and was maintained for 20 minutes.

During the first sessions, patients had head or neck painful symptoms at consultation time so symptoms improvement 
immediately after needle insertion was also evaluated. At each consultation, intensity in the beginning and end of the session was recorded and so on for eight sessions. As from the fourth session, patients would not necessarily present painful symptoms at consultation day, however they would follow the same routine: Hegu point evaluation and needle insertion on point A of the determined side and on point B if necessary and so on during eight weeks (Figure 1).

Paired $T$ test was used for statistical analysis to evaluate pain relief in each session, with significance level of $\mathrm{p}<0.05$ with regard to baseline pain intensity.

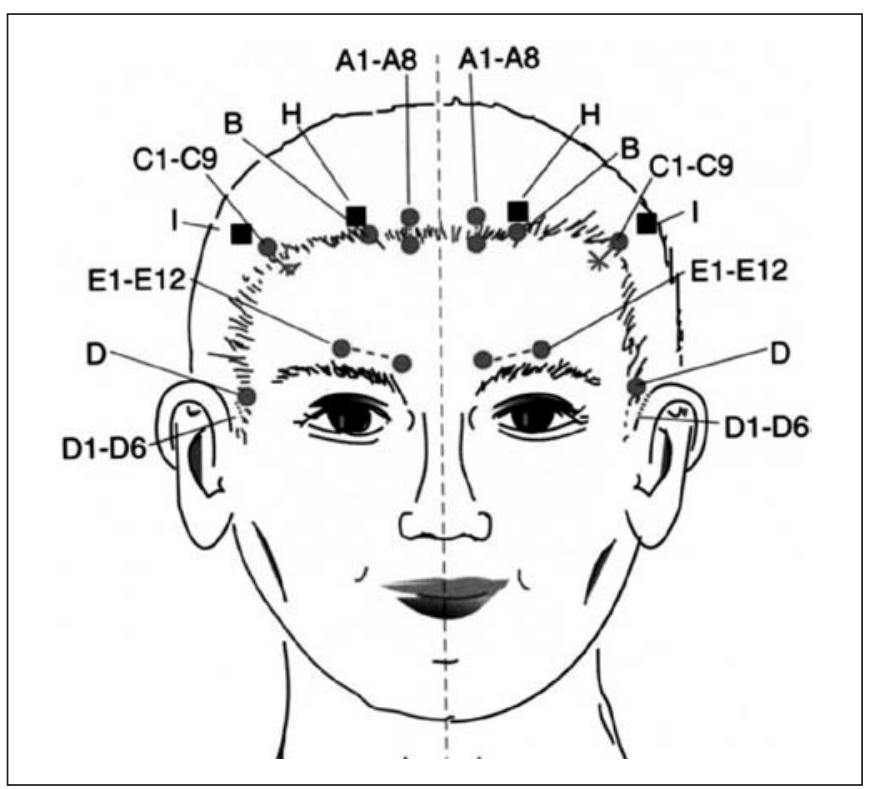

Figure 1. Basic Yin points ${ }^{7,9}$

Points A and B located in the skull and used by Yamamoto New Scalp Acunpucture technique
This study was approved by IBRATE-PR Research Ethics Committee, 313.486/2013.

\section{RESULTS}

From 34 volunteers, 24 were females and 10 were males. Pain report time has varied between 9 months and 15 years, with frequency of pain episodes above 3 times a week and mean age of 38 years. Major pain sites were: temporal $(n=40-11.76 \%)$, temporal and masseter $(n=8-23.52 \%)$, sternocleidomastoid and trapezius ( $n=5-14.70 \%)$, trapezius temporal sternocleidomastoid, masseter and trapezius $(n=17-50 \%)$.

Seven participants have given up the treatment along the eight weeks reporting factors such as difficult transportation to the research site or lack of time; six were excluded from the research due to consecutive non-attendance and one due to influenza followed by sinusitis which could change study results.

Twenty volunteers, all females, have completed the research. Pain intensity at baseline was 6 to 9 with mean of 8 for the YNSA group. At the end of eight sessions, 12 volunteers had zero pain, six had intensity 1 and decreased frequency. One participant had oscillation between consultations, either with pain relief or with recurrence, ending with intensity 5 , being that she had started with intensity 8 , and one patient ended with intensity 2 (Figure 2).

All volunteers have reported immediate pain decrease after needle insertion when pain was present at consultation.

Results have shown that YNSA technique was effective to decrease painful symptoms. Statistical test (paired t test) had significant results $(\mathrm{p}<0.05)$ in each evaluated week with regard to the first score reported by volunteers, that is baseline intensity (Table 1).

Table 1. Evaluation of pain intensity by the verbal numerical scale at each session during eight weeks

\begin{tabular}{|c|c|c|c|c|c|c|c|c|}
\hline$n$ & Initial VNS & $1^{\text {st }}$ session & $2^{\text {nd }}$ session & $3^{\text {rd }}$ session & $4^{\text {th }}$ session & $5^{\text {th }}$ session & $6^{\text {th }}$ session & $7^{\text {th }}$ session \\
\hline 1 & 8 & 5 & 4 & 3 & 2 & 2 & 1 & 1 \\
\hline 2 & 7 & 4 & 3 & 3 & 0 & 1 & 1 & 1 \\
\hline 3 & 9 & 4 & 3 & 2 & 0 & 0 & 0 & 0 \\
\hline 4 & 8 & 4 & $6^{*}$ & $8^{* *}$ & 2 & 4 & 2 & $5^{\star \star \star}$ \\
\hline 5 & 8 & 5 & 5 & 4 & 3 & 2 & 1 & 0 \\
\hline 6 & 9 & 5 & 5 & 3 & 2 & 1 & 1 & 0 \\
\hline 7 & 7 & 4 & 4 & 4 & 1 & 1 & 1 & 1 \\
\hline 8 & 8 & 5 & 4 & 3 & 2 & 0 & 1 & 2 \\
\hline 9 & 8 & 3 & 3 & 2 & 0 & 0 & 0 & 0 \\
\hline 10 & 9 & 4 & 4 & 3 & 2 & 1 & 0 & 0 \\
\hline 11 & 7 & 5 & 6 & 3 & 1 & 0 & 0 & 0 \\
\hline 12 & 7 & 3 & 4 & 2 & 0 & 0 & 0 & 0 \\
\hline 13 & 9 & 5 & 6 & 4 & 2 & 2 & 1 & 1 \\
\hline 14 & 8 & 3 & 3 & 2 & 2 & 1 & 1 & 1 \\
\hline 15 & 8 & 4 & 2 & 1 & 0 & 0 & 0 & 0 \\
\hline 16 & 6 & 5 & 3 & 3 & 2 & 1 & 0 & 0 \\
\hline 17 & 8 & 4 & 3 & 2 & 1 & 1 & 0 & 0 \\
\hline 18 & 9 & 4 & 3 & 2 & 0 & 0 & 0 & 0 \\
\hline 19 & 9 & 5 & 4 & 3 & 2 & 1 & 1 & 1 \\
\hline 20 & 7 & 4 & 3 & 2 & 1 & 0 & 0 & 0 \\
\hline
\end{tabular}

VNS = verbal numerical scale; ${ }^{*}$ emotional problem; ${ }^{* *}$ menstrual period; ${ }^{* *}$ mood instability. 


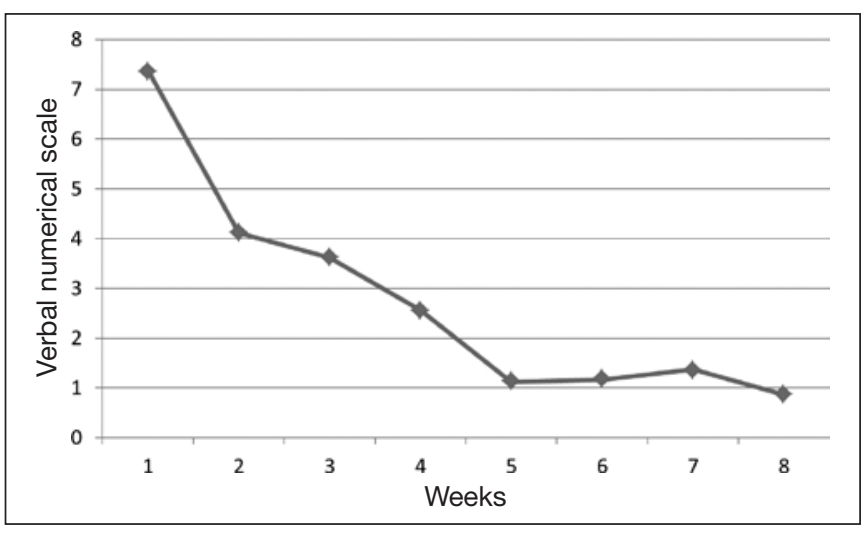

Figure 2. Behavior of mean score attributed to pain by the verbal numerical scale along treatment with Yamamoto New Scalp Acupuncture

\section{DISCUSSION}

Data support the technique as effective to relieve chronic musculoskeletal pain. YNSA is a type of acupuncture complementing Traditional Chinese Medicine (TCM), by providing new knowledge and insights on the electromagnetic circuit of the body ${ }^{13}$.

Differences in VNS scores for each patient have shown statistically significant improvement after therapy for the whole group of patients.

Although the analgesic effect mechanism of introducing needles, both in traditional and YNSA acupuncture, is not well known, inserting needles on tissue sensitive points to relieve pain is a well accepted practice ${ }^{12}$, and results of this study confirm that skull acupuncture has positive effect on pain, with clear improvement during 8 weeks of follow up and immediate effect when applied at pain moment. In a study by Irch et al. ${ }^{12}$ evaluating the efficiency of acupuncture on distant points to treat chronic cervical pain, distant points had a better result in relieving cervical pain and in improving movement, as compared to local needling.

This study has observed pain at consultation time and during the following eight weeks. All volunteers were equally treated and, regardless if pain was on neck, head or both, the technique was applied in the same manner. In all studied conditions, patients had significant pain relief soon after needle insertion and also gradual improvement of painful symptoms at every follow up during eight weeks. Clinically, short term results are less significant as compared to longlasting effects. However, immediate pain relief may motivate patients to go ahead with the treatment. This may be especially important for chronic pain because very often these are patients unhappy and discouraged by previous ineffective treatments and pain improvement helps gaining their confidence in acupuncture, and in this case YNSA was greatly beneficial, as well as having the advantage of not being applied to the painful region.

This result is in line with a study by Schokert, Schumpe $\&$ Nicoly ${ }^{11}$ to evaluate YNSA efficacy for locomotor system pain relief. Time for pain relief was subjectively studied with VNS, but also YNSA long term effects were evaluated $^{11}$. In this study, mean VNS scores calculated for 104 volunteers were 63/100 before treatment and 19/100 after treatment (measured in a scale of 100 points), as reported by patients immediately after the acupuncture session lasting 3 to 9 minutes. From these 104 patients, 45 (53.3\%) have reported relief, and 52 participants $(50 \%)$ have reported lack of symptoms for different periods of time. An important feature of this study is that needles were kept in place for just 3 to 9 minutes, aiming at evaluating the efficacy of YNSA in emergency conditions. In our study, this point was also addressed; the needle was maintained for 20 minutes in each session with excellent immediate analgesic results.

Action mechanism of this analgesia may be due to endogenous opioid peptides release, which is a well established mechanism for acupuncture ${ }^{14}$. Needle insertion may activate descending pain control inhibitory system, which is the most likely pain relief mechanism by needle stimulation, analgesic hyper-stimulation, and modulation of sensory nervous impulses of Melzack's gate control theory ${ }^{15}$.

With regard to variations on analgesic effects among volunteers, there has been important involvement of the emotional factor which, although not being the focus of this study, is of major importance. There is a close relationship between increase or instability of symptoms and the presence of psychological factors, such as job or family problems or mood instability, fact which was made very clear on volunteer 4 of this study.

A difficulty and limitation of this study was the lack of a group with Sham or placebo therapy to compare the analgesic effect, which would allow the blinding of participants as to possible improvement by the application of the technique; however, in all sessions, we avoided orienting participants about their possible sensations and about treatment effects. All volunteer reports were individually analyzed.

\section{CONCLUSION}

Our results point to the efficacy of one of several possibilities presented by acupuncture for pain relief, especially when the goal is immediate pain improvement. Although YNSA results are promising, further studies are still needed to evaluate this acupuncture modality to enhance its application and confidence on the technique.

\section{REFERENCES}

1. Kreling MC, da Cruz DA, Pimenta CA. [Prevalence of chronic pain in adult workers] Rev Bras. Enferm. 2006; 59(4):509-13. Portuguese.

2. Siviero M, Alvarez FK, Okada M, Teixeira MJ, de Siqueira JT, de Siqueira SR. Facial sensibility of patients with trigeminal neuralgias. Clín. Neurol. Neurosurg. 2011; 113(4):268-71.

3. Simons David G, Travell Janet G, Simons Lois S. Dor e disfunçāo miofascial. Manual dos pontos-gatilho. Volume 1. Parte Superior do Corpo. Artmed; 2005. 91-153p.

4. Von Korff M, Le Resche L, Dworkin SF. First onset of common pain symptoms: a prospective study of depression as a risk factor. Pain. 1993;55(2):251-8. 
5. Chou LW, Kao MJ, Lin JG. Probable mechanisms of needling therapies for myofascial pain control. Evid. Based. Complement Alternat Med. 2012;2012:705327.

6. Yamamoto T, Yamamoto H, Yamamoto MM. Nova craniopuntura de Yamamoto, NCY. São Paulo: Roca; 2007. 37-51p.

7. Oleson T. Auriculotherapy manual: Chinese and Western Suystems of ear acupuncture. Edinburgh: Churchill Livingstone; 1996. 165-270p.

8. Pomeranz B, Berman B. Scientific basis of acupuncture. In: Stux, Berman e Pomeranz (editores). Basics of Acupuncture. $5^{\text {th }}$. Berlin: Springer; 2003. 7-86p.

9. Camilotti BM. Cranioacupuntura de Yamamoto. Analgesia por acupuntura. Ominipax; 2013. 23-39p.

10. Feely RA. Yamamoto New Scalp Acupuncture (YNSA) acupoint frequency in the treatment of herniated lumbar disk, lumbar radiculopathy, and mechanical low back pain. Med Acupunct. 2006;6(2):20-3.

11. Schokert T, Schumpe G, Nicoly C. Effectiveness of Yamamoto New Scalp Acupuncture for the relief of pain of the locomotor system: an open, prospective topometrically controlled study. Ztschr Akup. 2002;2(1):93-100. German.

12. Irnich D, Behrens N, Gleditsch JM, Stör W, Wchreiber MA, Schöps P, et al. Immediate effects of dry needling and acupuncture at distant points in chronic neck pain: results of a randomized, double-blind, sham-controlled crossover trial. Pain. 2002;99(1-2):83-9.

13. Lewit K. The needle effect in the relief of myofascial pain. Pain. 1979;6(1):83-90.

14. Mayer DJ. Biological mechanisms of acupuncture. Prog Brain Res. 2000;122:457-77.

15. Melzack R. Myofascial trigger points: relation to acupuncture and mechanisms of pain. Arch Phys Med Rehabil. 1981;62(3):114-7. 